\title{
E-cadherin-catenin complex in the rat ovary: cell-specific expression during folliculogenesis and luteal formation
}

\author{
K. Sundfeldt ${ }^{1}$, Y. Piontkewitz ${ }^{1 *}$, H. Billig ${ }^{1}$ and L. Hedin ${ }^{1,2+}$ \\ ${ }^{1}$ Department of Physiology, Göteborg University, Göteborg, Sweden; and ${ }^{2}$ Department of Anatomy and Cell Biology, University of Bergen, \\ Bergen, Norway
}

\begin{abstract}
The cadherins and their cytoplasmic counterparts, the catenins, form the adherens junctions, which are of importance for tissue integrity and barrier functions. The development and maturation of the ovarian follicle is characterized by structural changes, which require altered expression or function of the components involved in cell-cell contacts. The present study examined the cell-specific localization and temporal expression of epithelial cadherin (E-cadherin) and $\alpha$ - and $\beta$-catenin during follicular development, ovulation and corpus luteum formation in the immature gonadotrophin- and oestrogen-stimulated rat ovary. Immunohistochemistry and immunoblotting demonstrated the expression of E-cadherin in theca and interstitial cells of immature ovaries before and after injection of equine chorionic gonadotrophin (eCG). E-cadherin was not detected in granulosa cells, except in the preantral follicles located to the inner region of the ovary. The content of E-cadherin in theca and interstitial cells decreased after an ovulatory dose of hCG. Granulosa cells of apoptotic follicles did not express E-cadherin. Oestrogen treatment (diethylstilboestrol) of immature rats for up to 3 days did not result in a measurable expression of E-cadherin in granulosa cells. $\alpha$ - and $\beta$-catenin were expressed in all ovarian compartments. The concentration of $\beta$-catenin was constant during the follicular phase, whereas the content of $\alpha$-catenin decreased in granulosa cells after treatment with diethylstilboestrol or hCG. The expression of $\alpha$-catenin was also reduced in theca and interstitial cells after hCG. $\alpha$ - and $\beta$-catenin were present in most ovarian cells at all stages of folliculogenesis. Therefore, the catenins have the potential to associate with different members of the cadherin family and to participate in the regulation of cytoskeletal structures and intracellular signalling. The restricted expression of Ecadherin in granulosa cells of preantral follicles indicates a role in the recruitment of these follicles to subsequent cycles. The specific decrease of $\alpha$-catenin in granulosa cells and the reduction of both $\alpha$-catenin and E-cadherin in theca cells of ovulatory follicles might reflect some of the molecular changes in cell-cell adhesion associated with ovulation and luteinization.
\end{abstract}

\section{Introduction}

The mammalian ovary undergoes dynamic morphological changes during the reproductive cycle. The different ovarian compartments are subject to both proliferation and differentiation events, which are regulated by endocrine and paracrine factors (Richards, 1994). In addition to these soluble signalling molecules, the physical intercellular communication through cell-cell adhesion is important in the maintenance of tissue integrity and function (Gumbiner

*Present address: School of Biological Sciences, The Weizman Institute,

Rehovot, Israel.

${ }^{+}$Correspondence address: Department of Anatomy and Cell Biology,

University of Bergen, Årstadveien 19, N-5009 Bergen, Norway.

Received 27 April 1999. and McCrea, 1993). The cadherins are a group of proteins localized to the plasma membrane that are involved in the control of cell-cell adhesion ('classical cadherins') (Takeichi, 1991). This family consists of more than 20 members with common structural motifs, for example an extracellular homophilic binding portion, a transmembrane part and a cytoplasmic catenin-binding domain. One member of this family, epithelial cadherin (E-cadherin), plays a key role during tissue development and differentiation of many organs (Takeichi, 1991). The cytoplasmic portion of Ecadherin binds a group of connecting proteins, the catenins, which mediate the signalling events from the extracellular environment to the interior of the cell, for example to cytoskeletal structures ( $\alpha$-catenin) (Geiger and Ayalon, 1992) or to the nucleus ( $\beta$-catenin) (Molenaar et al., 1996; Behrens et al., 1996). 
Farookhi and Blaschuk (1989) reported the expression of Ecadherin protein in rat granulosa cells in vitro and suggested a positive regulatory role for oestradiol. MacCalman et al. (1994a) reported the presence of E-cadherin $\mathrm{mRNA}$ in the mouse ovary in vivo, although cell-specific expression was not examined. Studies have also indicated a function for E-cadherin as antiapoptotic molecules since E-cadherin was present in ovine granulosa cells of healthy follicles, whereas expression was not detected in atretic follicles (Ryan et al., 1996). Moreover, another member of the cadherin family, neuronal cadherin $(\mathrm{N}-$ cadherin) inhibits apoptosis of rat granulosa cells in vitro (Peluso et al., 1996). In the human menopausal ovary, expression of E-cadherin is negligible, except for inclusion cysts in which the surface epithelial cells that line the cysts show strong expression of E-cadherin (Maines-Bandiera and Auersperg, 1997; Sundfeldt et al., 1997). Furthermore, benign and malignant ovarian tumours derived from surface epithelial cells show an increased expression of E-cadherin (Maines-Bandiera and Auersperg, 1997; Sundfeldt et al., 1997).

The E-cadherin-catenin complex is also present in the primate corpus luteum in which E-cadherin is expressed primarily during the early luteal phase. The catenins showed a different pattern compared with E-cadherin and were expressed in high concentration in the mid-luteal phase. Expression of E-cadherin was not detected in the regressing corpus luteum (Khan-Dawood et al., 1996a,b). Butz and Larue (1995) reported the presence of catenins in the mouse ovary; however, to date, the expression of catenins has not been reported in the rat ovary.

The present study was designed to examine the cellspecific localization and temporal expression of E-cadherin, $\alpha$ - and $\beta$-catenin in vivo during follicular development from the antral to the preovulatory stage, the ovulatory period and luteal formation in equine chorionic gonadotrophin (eCG)-primed immature rats and in untreated cyclic rats. In addition, the specific effect of oestrogens was investigated in diethylstilboestrol (DES)-treated immature rats and the expression of E-cadherin was examined in apoptotic follicles.

\section{Materials and Methods}

\section{Animals and experimental protocols}

Immature Sprague-Dawley rats (25 days old) from B\&K Universal AB (Stockholm) were injected s.c. with $10 \mathrm{iu}$ eCG (PMSG/eCG; Sigma, St Louis, MO) in $0.1 \mathrm{ml}(0.9 \%(\mathrm{w} / \mathrm{v})$ $\mathrm{NaCl}$ ) to initiate follicular growth. Rats at the preovulatory stage (27 days old) were injected i.p. with 10 iu hCG (Serono, Rome) to imitate the endogenous LH peak (Piontkewitz et al., 1997). Immature rats ( 25 days old) were also used to examine the effects of oestrogens. These animals were injected s.c. twice a day $\left(1 \mathrm{mg} \mathrm{day}^{-1}\right)$ for 1, 2 or 3 days with DES (groups DES1, DES2, DES3) (Sigma). DES was dissolved in ethanol, diluted in corn oil (5\% ethanol:95\% corn oil) (Billig et al., 1993). One group of animals (DES3) received 10 iu hCG i.p. $12 \mathrm{~h}$ after the last injection of DES (Louvet et al., 1975). The rats were killed by decapitation at different time points as indicated in the figures. Cyclic (mature) rats (Sprague-Dawley; 70-80 days of age) were used for the immunohistochemistry.
All experiments were approved by the Ethics Committee of the Medical Faculty, Göteborg University, and were carried out according to the principles and procedures outlined in the NIH Guide and Use of Laboratory Animals.

\section{Tissue preparation}

Granulosa cells were obtained by puncture of follicles and were separated from the remaining residual ovarian tissues (Piontkewitz et al., 1997). In one set of experiments, follicles were isolated from the remaining residual ovarian tissues. The follicles were separated into granulosa and theca cells (Nordenström and Hamberger, 1981). Tissue extracts were prepared by homogenization of the tissue in a PE buffer (10 mmol potassium phosphate buffer $\mathrm{l}^{-1}(\mathrm{pH}$ 6.8) and $1 \mathrm{mmol}$ EDTA $\mathrm{l}^{-1}$ ) containing $10 \mathrm{mmol} \mathrm{3-[(3-cholamidopropyl)dim-}$ ethyl-ammonio] 1-propan sulfonate (CHAPS) $1^{-1}$, aprotinin (200 kallikrein inhibitory units $\left.\mathrm{ml}^{-1}\right)$, leupeptin $\left(1 \mathrm{mg} \mathrm{ml}^{-1}\right)$, pepstatin $\left(1 \mathrm{mg} \mathrm{ml}^{-1}\right)$ and Pefablock ${ }^{\circledR}\left(1 \mathrm{mg} \mathrm{ml}^{-1}\right)$ (Boehringer Mannheim, Mannheim). The homogenate was then sonicated $(2 \times 15 \mathrm{~s})$ and centrifuged $\left(10000 \mathrm{~g}, 10 \mathrm{~min}, 4^{\circ} \mathrm{C}\right)$. The supernatants were stored at $-70^{\circ} \mathrm{C}$ until analysis. The protein content was measured as described by Piontkewitz et al. (1997).

\section{Immunoblotting}

The protein samples were diluted in SDS sample buffer, boiled for $5 \mathrm{~min}$ and loaded onto a one-dimensional SDSpolyacrylamide gel $(8 \%(\mathrm{w} / \mathrm{v})$ Tris-glycine) (NOVEX, San Diego, CA). Protein $(30 \mu \mathrm{g})$ was loaded into each lane. The proteins were transferred to a polyvinyldiflouride (PVDF) membrane (Millipore, Bedford, MA) using a blotting system (NOVEX). All antibodies were from Transduction Laboratories (Lexington, KY). The membrane was incubated with specific antibodies against E-cadherin (catalogue no. C20820; dilution 1:1000), $\alpha$-catenin (catalogue no. C21620; dilution 1:1000) or $\beta$-catenin, (catalogue no. C19220; dilution 1:2000). Pre-stained standards (SeeBlue; NOVEX) were used as molecular mass markers. Immunoreactive protein was visualized by chemiluminescence using an alkaline phosphatase-conjugated secondary antibody (goat-antimouse) and CDP-Star ${ }^{\circledR}$ or AMPPD (chemiluminescent enzyme substrates) (Tropix, Bedford, MA) (Bronstein et al., 1992). The membrane was exposed to ECL film (Amersham, Aylesbury) at room temperature for $10-90 \mathrm{~s}$ and subsequently developed. The results are presented with a representative immunoblot from each experiment. Each experiment was repeated at least three times.

\section{Immunohistochemistry}

Ovaries were dissected and incubated in $4 \%(\mathrm{w} / \mathrm{v})$ paraformaldehyde-PBS ( $\mathrm{pH} \quad 7.3)$ at $4^{\circ} \mathrm{C}$ for $2 \mathrm{~h}$ and transferred to $21 \%(\mathrm{w} / \mathrm{v})$ sucrose-PBS at $4^{\circ} \mathrm{C}$ overnight. The tissue was embedded in Tissue-Tek II OCT compound (Miles, Elkhart, IN) and frozen in cold isopentane. 
Cryosections (10 $\mu \mathrm{m}$ thick; Leitz cryostat, Rockleigh, NJ) were placed on superfrost-PLUS-slides (Menzel-Gläser, Braunschweig), air dried and stored at $-20^{\circ} \mathrm{C}$. The slides were hydrated with cold PBS and blocked with 5\% (w/v) non-fat milk for $30 \mathrm{~min}$ before the addition of the primary antibodies to E-cadherin (dilution 1:100), $\alpha$-catenin (dilution $1: 100$ ) and $\beta$-catenin (dilution 1:200). The antibodies against E-cadherin and $\beta$-catenin were the same as used for immunoblotting (monoclonal antibodies), whereas the antibody against $\alpha$-catenin was of polyclonal origin (catalogue no. sc-1495, Santa Cruz Biotechnology, Santa Cruz, CA). The antibodies were diluted in buffer solution (PBS with $1 \%$ BSA, $0.2 \%(\mathrm{v} / \mathrm{v})$ Triton-X100, 0.1\% (w/v) sodium azide). Bound antibodies were visualized by biotinylated secondary horse anti-mouse antibodies (Ecadherin, $\beta$-catenin) or anti-goat antibodies ( $\alpha$-catenin) (Vector, Burlingham, CA) and streptavidin-fluorescein isothiocyanate (FITC) (Amersham). Rat serum (dilution 1:20) was added $30 \mathrm{~min}$ before the addition of secondary antibodies to block non-specific binding. Sections were mounted with Moviol/Dabco mounting medium $(0.4 \%$ (w/v) Moviol; Hoechst AG, Kansas City, MO) in 30\% (v/v) glycerol with the addition of $2.5 \%$ (w/v) Dabco (4diazabicyclo (2.2.2) octane (Fluka, Buchs) (Sundfeldt et al., 1997). In control sections, which showed only negligible signals, the first antibody was replaced by normal mouse IgG (Jackson Immuno Research, IR) (E-cadherin, $\beta$-catenin) or 5\% $(\mathrm{w} / \mathrm{v})$ non-fat milk ( $\alpha$-catenin). Sections were stained with haematoxylin and eosin for observation of morphology. The sections were viewed and photographed with a Nikon microphot FX fluorescence microscope (Nikon, Japan).

\section{In situ DNA 3'-end labelling}

Ovaries were fixed, cryosectioned (see details for immunohistochemistry) and then analysed according to the protocol of Billig et al. (1994) with slight modifications. Briefly, sections were hydrated and treated with proteinase $\mathrm{K}$ $\left(10 \mu \mathrm{g} \mathrm{ml}^{-1}\right.$; Boehringer Mannheim) for $15 \mathrm{~min}$ at $37^{\circ} \mathrm{C}$ in a humidified chamber and washed three times in Tris-buffer. DNA 3'-end labelling with non-radioactive digoxigeninddUTP (dig-ddUTP) was performed after incubation for 10 min in terminal transferase buffer at room temperature. Terminal transferase ( $1 \mathrm{U} \mathrm{ml}^{-1}$; Boehringer Mannheim), digddUTP (5 mmol 1-1; Boehringer Mannheim), and ddATP (45 mmol 1 ${ }^{-1}$; Pharmacia, Uppsala) were added in fresh buffer and incubated at $37^{\circ} \mathrm{C}$ in a humidified chamber for $1 \mathrm{~h}$. The ddNTPs were used to prevent 'tailing' and to allow the incorporation of one nucleotide per free DNA 3'-end, thus ensuring a more quantitative assay. After three washes in Tris buffer, the sections were incubated with blocking buffer for $30 \mathrm{~min}$ at room temperature before the addition of antidigoxigenin antibody conjugated to alkaline phosphatase. After incubation with the antibody at room temperature for 2 $h$ in a humidified chamber, the slides were washed three times in Tris-buffer and equilibrated in alkaline phosphatase buffer before the addition of substrates for alkaline phosphatase. After 10-20 min in the dark, the colour reaction was terminated with $10 \mathrm{mmol}$ Tris $\mathrm{l}^{-1}$ and 1 mmol EDTA $\mathrm{l}^{-1}$,
$\mathrm{pH}$ 8. When the antibody conjugate was omitted from the procedure, no colour reaction was detected (data not shown). The sections were viewed and photographed with a Nikon microphot FX fluorescence microscope (Nikon, Japan).

\section{Results}

\section{Cell-specific localization and expression of E-cadherin during folliculogenesis and luteal formation}

The cell-specific localization of E-cadherin, $\alpha$ - and $\beta$ catenin was determined in ovaries from immature rats (day $25)$, in preovulatory ovaries (48 h after eCG), in preovulatory ovaries 4, 8, 12 and $24 \mathrm{~h}$ (day 1 corpus luteum) after hCG. Ovaries of cyclic rats were also examined. Staining of the epithelial cells of the oviduct adjacent to the ovary was used as a positive control for the immunohistochemistry (data not shown). Protein extract of the oviduct was also used as a positive control in immunoblotting.

E-cadherin showed strong and specific staining of interstitial cells at all stages of follicular development and to theca cells of antral and preovulatory follicles. In immature ovaries, that is before injection of eCG, granulosa cells in some preantral follicles stained positively for E-cadherin (Fig. 1a). No such staining of granulosa cells was detected in preovulatory follicles $48 \mathrm{~h}$ after eCG (Fig. 1b) or $4 \mathrm{~h}$ after hCG (Fig. 1c). In contrast, granulosa cells localized primarily to the mural layers of preantral follicles in the cortical region of the ovary $4 \mathrm{~h}$ after hCG expressed E-cadherin similar to such follicles in the immature ovary (Fig. 1d). The granulosa cells of ovulatory follicles remained negative at $8 \mathrm{~h}$ (Fig. 1e) and $12 \mathrm{~h}$ (Fig. 1f) after hCG. The theca cells of these follicles showed faint staining (Fig. 1e) or no staining (Fig. 1f), whereas the surface epithelium stained positive for Ecadherin (Fig. 1e,f). The luteal cells of a cyclic ovary expressed E-cadherin (Fig. 1g) although the signal was less intense compared with the interstitial tissue and theca cells of a preovulatory follicle (Fig. 1h).

The expression of E-cadherin was also evaluated by immunoblotting. A major band of $120 \mathrm{kDa}$ was detected in residual ovarian tissues (Fig. 2). A smaller band ( $80 \mathrm{kDa}$ ) of lower intensity was also present in these samples, representing the proteolysed and soluble form of E-cadherin described earlier (Damsky et al., 1983). The signal for Ecadherin in granulosa cells was weak or not detectable in all samples (Fig. 2). The residual ovarian tissues of immature ovaries showed a higher content compared with these tissues at later stages of follicular development. A substantial decrease was noted in residual ovarian tissues after hCG (Fig. 2).

The cell-specific localization was analysed further with dissection of immature and preovulatory ovaries into granulosa and theca cells and residual ovarian tissues (Fig. 3). The signal for E-cadherin was negligible in granulosa cells, whereas both theca cells and residual ovarian tissues showed high expression in both immature and preovulatory ovaries, although the expression was lower in the preovulatory samples (Fig. 3).

Sections of ovary from cyclic and DES-primed rats were 

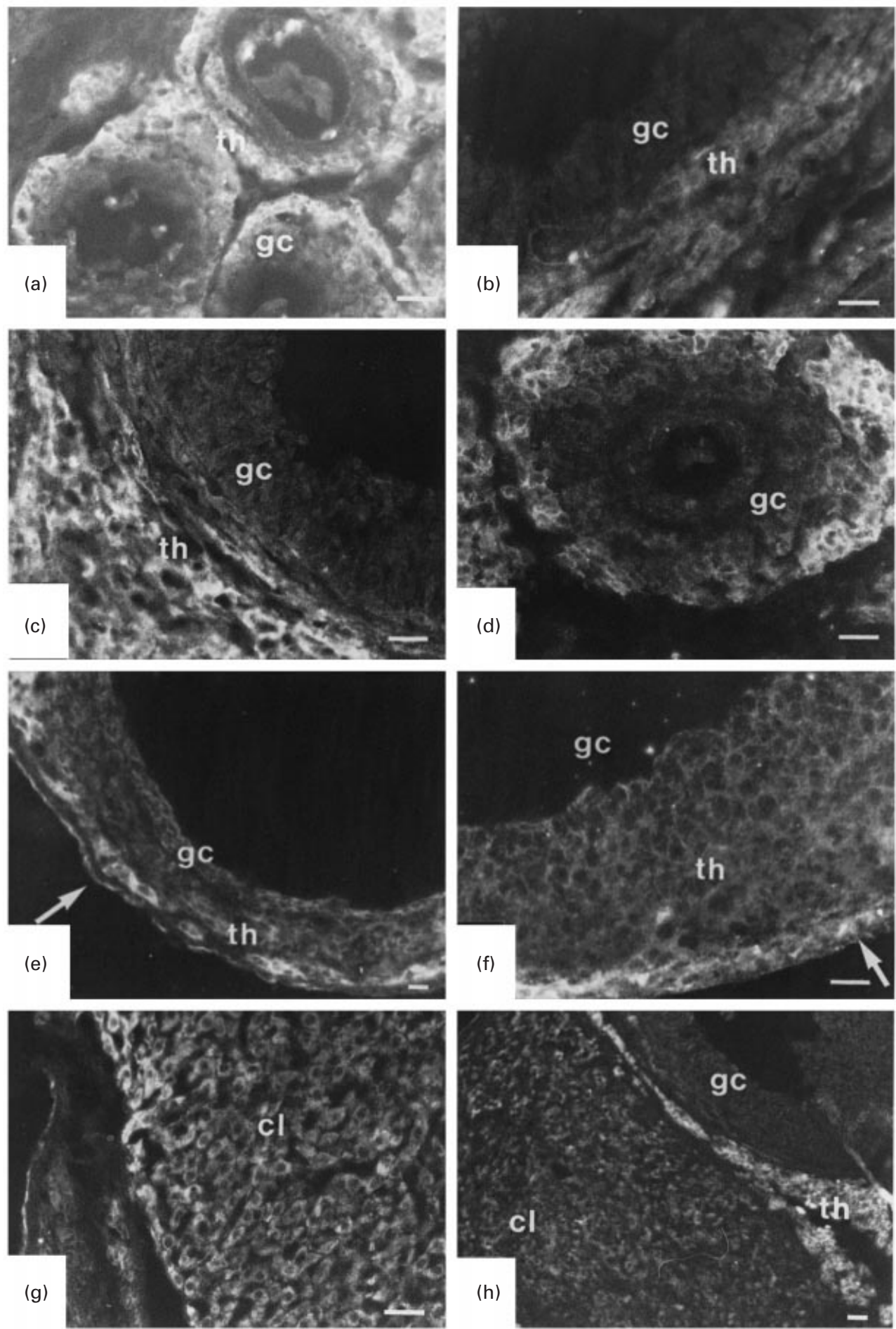

Fig. 1. Immunohistochemical localization of E-cadherin during the follicular and luteal phase in rats. (a) Preantral follicles of an immature ovary (day 25). (b) Preovulatory follicle (day 27). (c) Ovulatory follicle at $4 \mathrm{~h}$ after hCG. (d) Preantral follicle localized to the cortical region at $4 \mathrm{~h}$ after hCG. (e) Ovulatory follicle at $8 \mathrm{~h}$ after hCG. (f) Ovulatory follicle at $12 \mathrm{~h}$ after hCG. (g) Corpus luteum of a cyclic ovary. (h) Corpus luteum and a preovulatory follicle of a cyclic ovary. Arrows show the surface epithelial cells. cl: corpus luteum; gc: granulosa cells; th: theca cells. Scale bars represent $50 \mu \mathrm{m}$.

DNA 3'-end labelled in situ to examine the presence or absence of apoptotic processes in follicles or corpora lutea expressing E-cadherin. Consecutive sections were stained for apoptosis, E-cadherin, and haematoxylin and eosin. A section of a preovulatory follicle and an adjacent corpus luteum (cyclic rat) is shown (Fig. $4 \mathrm{a}-\mathrm{c}$ ). The signal for E- 


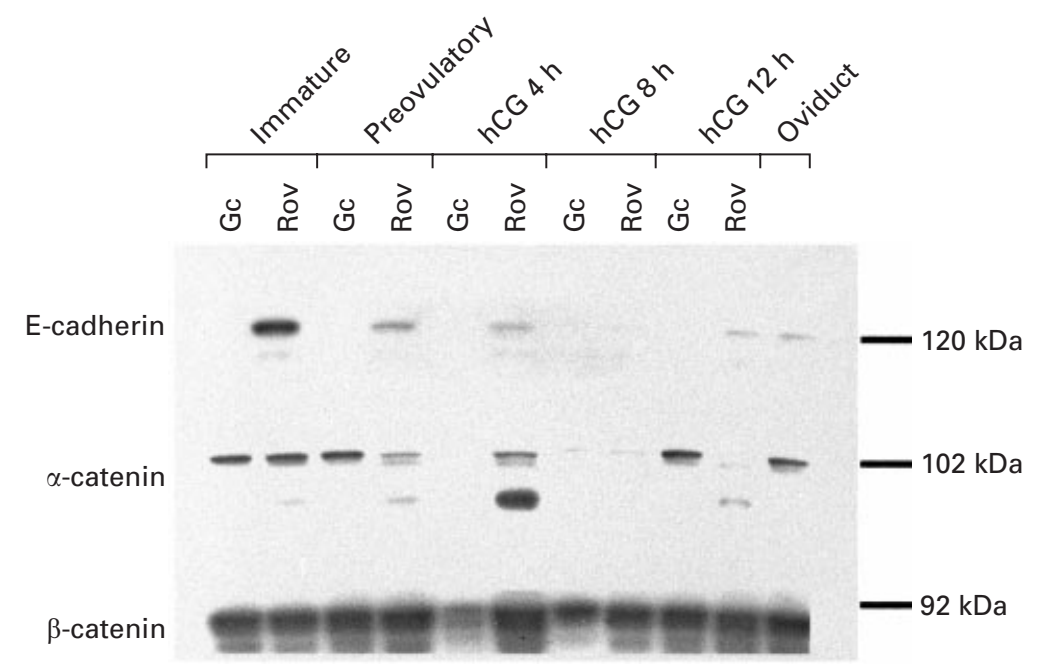

Fig. 2. Immunoblotting of E-cadherin and $\alpha$ - and $\beta$-catenin in rat ovaries. Results are from immature ovaries (immature), at $48 \mathrm{~h}$ after eCG (preovulatory) and after hCG $(4 \mathrm{~h}, 8 \mathrm{~h}, 12 \mathrm{~h})$. The ovaries were separated into granulosa cells (Gc) and residual ovarian tissues (Rov). The oviduct was used as a positive control.

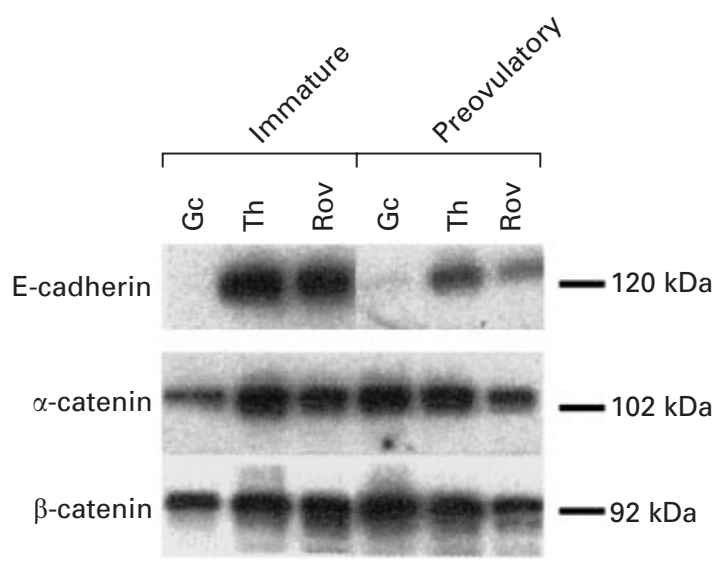

Fig. 3. Immunoblotting of E-cadherin and $\alpha$ - and $\beta$-catenin in follicles of immature rat ovaries (immature) and rat ovaries $48 \mathrm{~h}$ after eCG (preovulatory) separated into granulosa cells (Gc), theca cells (Th) and residual ovarian tissues (Rov).

cadherin was present only in the theca and interstitial cells and to a lesser extent in the corpus luteum (Fig. 4b). This section was negative for apoptosis (Fig. 4a). In two antral follicles (DES-primed rat) in which there were indications of ongoing apoptosis in the granulosa cells (Fig. 4d), no staining for E-cadherin was detected in granulosa cells. The theca cells of the apoptotic follicle expressed E-cadherin (Fig. 4e). Similarly, E-cadherin expression was not detectable in an antral follicle (cyclic rat) in which apoptosis was marked (Fig. 5a,b). The presence of E-cadherin could only be demonstrated in theca and interstitial cells (Fig. 5b) and in the surface epithelium (arrow, Fig. 5b).
Cell-specific localization and expression of $\alpha$-and $\beta$-catenins during folliculogenesis and luteal formation

The expression of $\alpha$-catenin was demonstrated in almost all types of cell in the ovary (Fig. 6). The signal was more intense in theca and interstitial cells compared with granulosa cells in the immature ovary (Fig. 6a), whereas granulosa cells of preovulatory follicles expressed more $\alpha$ catenin compared with theca cells. The surface epithelial cells were also positively stained (Fig. 6b). A decrease in the granulosa cells of ovulatory follicles was noted $4 \mathrm{~h}$ after hCG (Fig. 6c). The staining of these cells was more prominent at 8 h (Fig. 6d) and $12 \mathrm{~h}$ (Fig. 6e) compared with that at $4 \mathrm{~h}$ (Fig. 6c). No staining was observed in the theca cells at $12 \mathrm{~h}$, whereas the surface epithelial cells expressed $\alpha$-catenin (Fig. $6 e)$. The protein was also expressed in the early corpus luteum (Fig. 6f).

The localization of $\alpha$-catenin to granulosa and theca cells and residual ovarian tissues was confirmed with immunoblotting; there was an increase in granulosa cells from immature to preovulatory follicles (Fig. 3). There was a decrease in $\alpha$-catenin in granulosa cells at $4 \mathrm{~h}$ after hCG, whereas the expression in the residual ovarian tissues remained high (Fig. 2). There was a gradual increase in the granulosa cells with time after hCG, in particular at 8 and 12 $\mathrm{h}$. The expression was more prominent in granulosa cells of preovulatory follicles and ovulatory follicles $12 \mathrm{~h}$ after hCG compared with residual ovarian tissues. Interestingly, the immunoblotting revealed a low molecular mass band of approximately $70 \mathrm{kDa}$ in addition to the full-length protein $(102 \mathrm{kDa})$ (Fig. 2). This band was present mainly in the residual ovarian tissues (Fig. 2).

$\beta$-catenin was expressed in most ovarian cells in the immature (Fig. 7a) and preovulatory ovary (Fig. 7b). In contrast to E-cadherin, the granulosa cells of antral (Fig. 7a) 


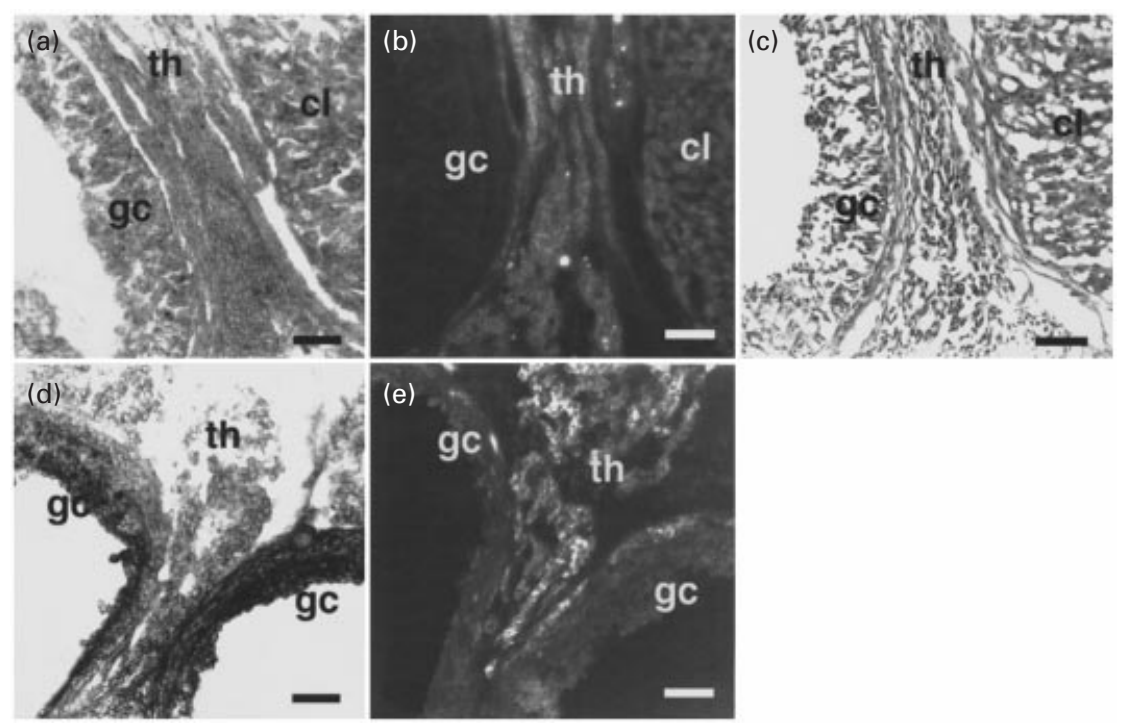

Fig. 4. Immunohistochemistry, in situ DNA 3'-end labelling, and haematoxylin and eosin staining of a cyclic rat ovary. $(a, b, c)$ Consecutive sections of the same ovary: (a) DNA 3'-end labelling with no positive staining of a preovulatory follicle or corpus luteum; (b) staining for E-cadherin; (c) haematoxylin and eosin staining. (d,e) Consecutive sections of the same ovary: (d) DNA 3'-end labelling showing two atretic apoptotic follicles; (e) staining for Ecadherin. cl: corpus luteum; gc: granulosa cells; th: theca cells. Scale bars represent $50 \mu \mathrm{m}$.
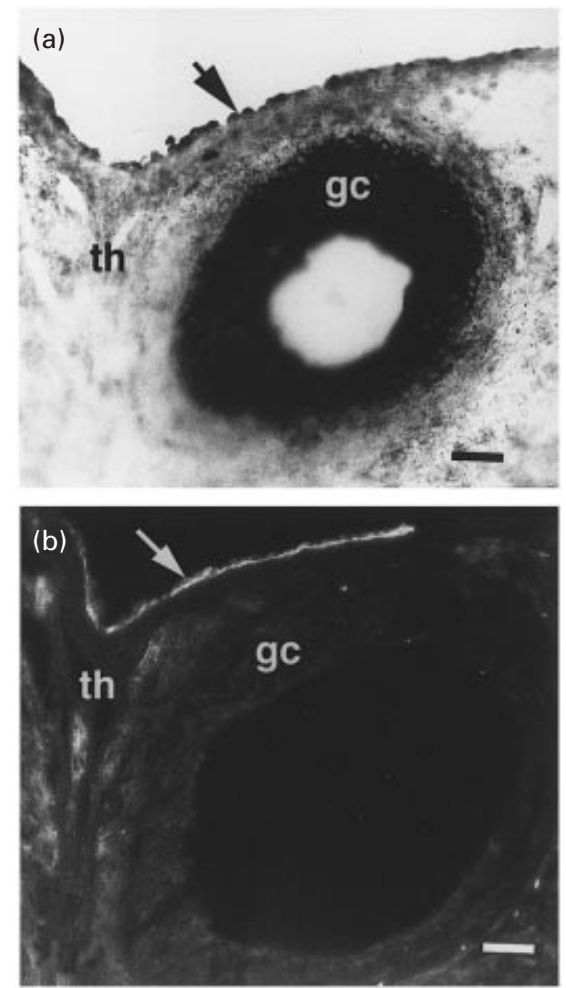

Fig. 5. Immunohistochemistry and in situ DNA $3^{\prime}$-end labelling of a cyclic rat ovary. (a) DNA 3 '-end labelling of an antral atretic apoptotic follicle. (b) Staining for E-cadherin in the same follicle shown in (a). Arrows show the surface epithelial cells. gc: granulosa cells; th: theca cells. Scale bars represent $50 \mu \mathrm{m}$. and preovulatory follicles (Fig. 7b) were positively stained for $\beta$-catenin. The granulosa, theca and interstitial cells continued to express $\beta$-catenin at $4 \mathrm{~h}$ (Fig. 7c), $8 \mathrm{~h}$ (Fig. 7d) and $12 \mathrm{~h}$ (Fig. 7e) after hCG and the granulosa cells contained more $\beta$-catenin compared with the theca cells. Luteal cells of the cyclic ovary were also stained (Fig. 7f). The intracellular distribution of $\beta$-catenin was more diffuse (cytoplasmic) in the luteal cells and not restricted to the plasma membrane, as in the granulosa cells of the ovulatory follicle at $12 \mathrm{~h}$ (Fig. 7e). $\beta$-catenin was also expressed in the surface epithelial cells in the immature (Fig. 7a, arrow) and ovulatory ovary (Fig. 7c, arrow) and in the ovary during the luteal phase (Fig. 7f, arrow).

Immunoblotting demonstrated the distribution of $\beta$ catenin to granulosa and theca cells and residual ovarian tissues (Fig. 3). No major changes were detected in the contents of $\beta$-catenin in granulosa cells or residual ovarian tissues before or after hCG (Fig. 2).

\section{Effects of DES and hCG on E-cadherin and $\alpha$-and $\beta$-catenin}

Ovaries of intact immature rats treated with DES for up to 3 days were used to examine the effect of oestrogens on the expression of E-cadherin and $\alpha$ - and $\beta$-catenin. Treatment with DES resulted in a slight decrease in the content of Ecadherin in the residual ovarian tissues compared with the content before DES injections. The content in granulosa cells was negligible and did not change in response to DES or hCG (Fig. 8). A decrease in $\alpha$-catenin was observed in granulosa cells at 1 day after DES treatment compared with the content before treatment. The expression remained low 

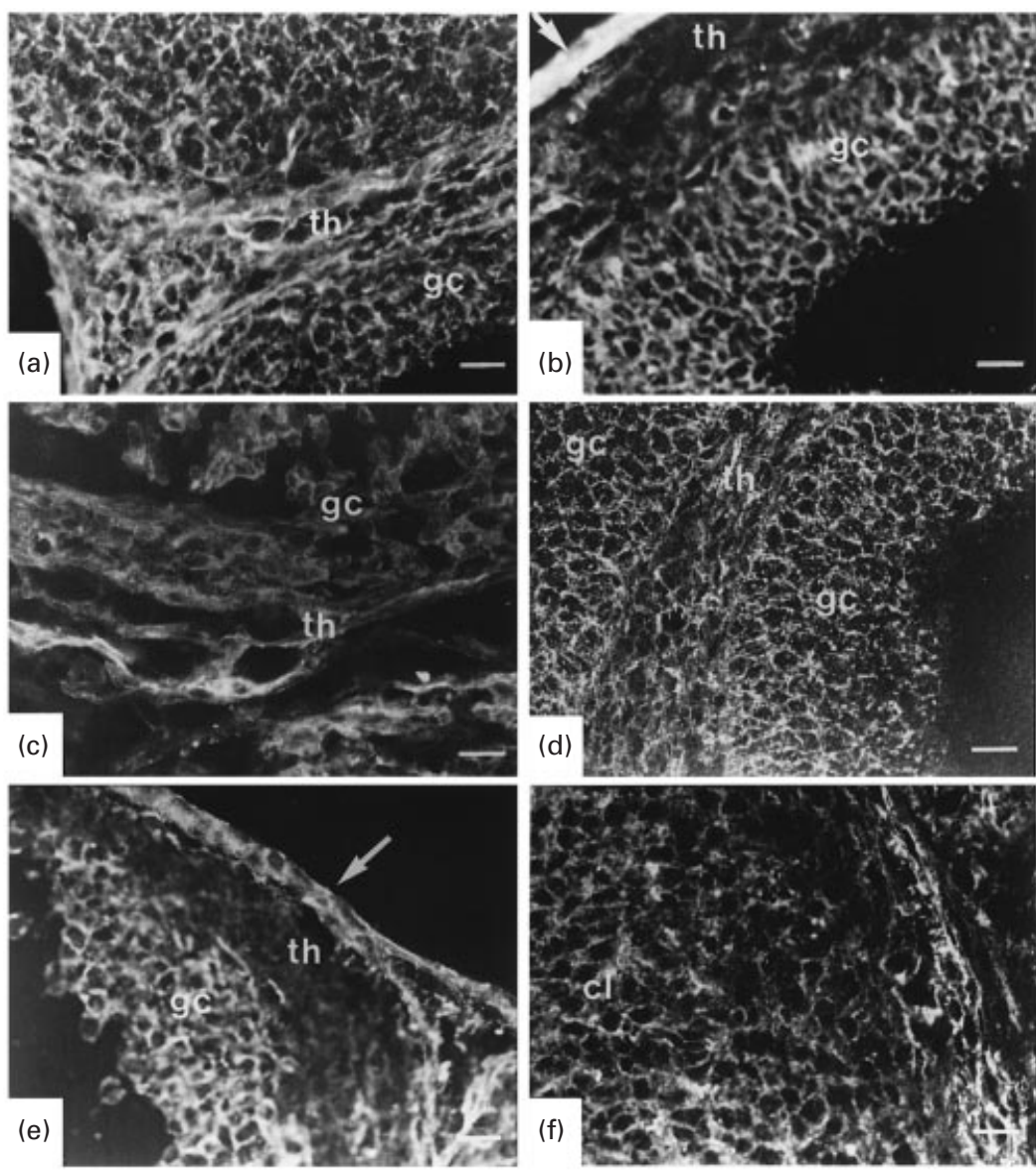

Fig. 6. Immunohistochemical localization of $\alpha$-catenin during the follicular and luteal phases in rats. (a) Antral follicles of an immature ovary (day 25). (b) Preovulatory follicle (day 27). (c) Ovulatory follicle at $4 \mathrm{~h}$ after hCG. (d) Ovulatory follicle at $8 \mathrm{~h}$ after hCG. (e) Ovulatory follicle at $12 \mathrm{~h}$ after hCG. (f) Corpus luteum from cyclic ovary. Arrows show the surface epithelial cells. cl: corpus luteum; gc: granulosa cells; th: theca cells. Scale bars represent $50 \mu \mathrm{m}$.

in granulosa cells after 2 and 3 days of DES treatment, but an increase was observed in residual ovarian tissues at these time points (Fig. 8). An additional band with an apparent molecular mass of $70 \mathrm{kDa}$ was observed in residual ovarian tissues after DES treatment. The expression of $\beta$-catenin was strong in both granulosa cells and residual ovarian tissues and was not changed by DES or hCG (Fig. 8).

\section{Discussion}

The present study examined the expression and localization of E-cadherin and $\alpha$ - and $\beta$-catenin in vivo in the rat ovary from immature, eCG-primed and DES-treated rats. These proteins participate in the formation of the adherens junctions, which have been implicated to play an important role during early stages of follicular development (Amsterdam et al., 1992). In primordial follicles, both gap junctions and adherens junctions are present, but in response to gonadotrophins (FSH and eCG) the granulosa cells lose the adherens junctions and desmosomes (Amsterdam et al.,
1992). In contrast, the number and the size of the gap junctions increases in these cells (Amsterdam et al., 1992).

In the present study, the expression of E-cadherin in granulosa cells was negligible in antral, preovulatory and ovulatory follicles. However, immunohistochemistry showed E-cadherin in granulosa cells of preantral follicles of immature unstimulated ovaries. This finding is in agreement with earlier studies (Ryan et al., 1996) that reported high contents of E-cadherin protein in neonatal and immature pig ovaries compared with ovaries in cyclic and pregnant pigs. In the study of Ryan et al. (1996), granulosa and theca cells were separated from medium-sized follicles and granulosa cells were shown to be the major source of E-cadherin. This is in contrast to the results of the present study in which Ecadherin was localized predominantly to the theca and interstitial cells during follicular development in rats. This discrepancy might be due to species differences since the two studies used the same source of antibodies against Ecadherin. The localization of E-cadherin to the theca cells in the pig ovary was interpreted as a result of contaminating granulosa cells in the theca cell preparation, since the latter 

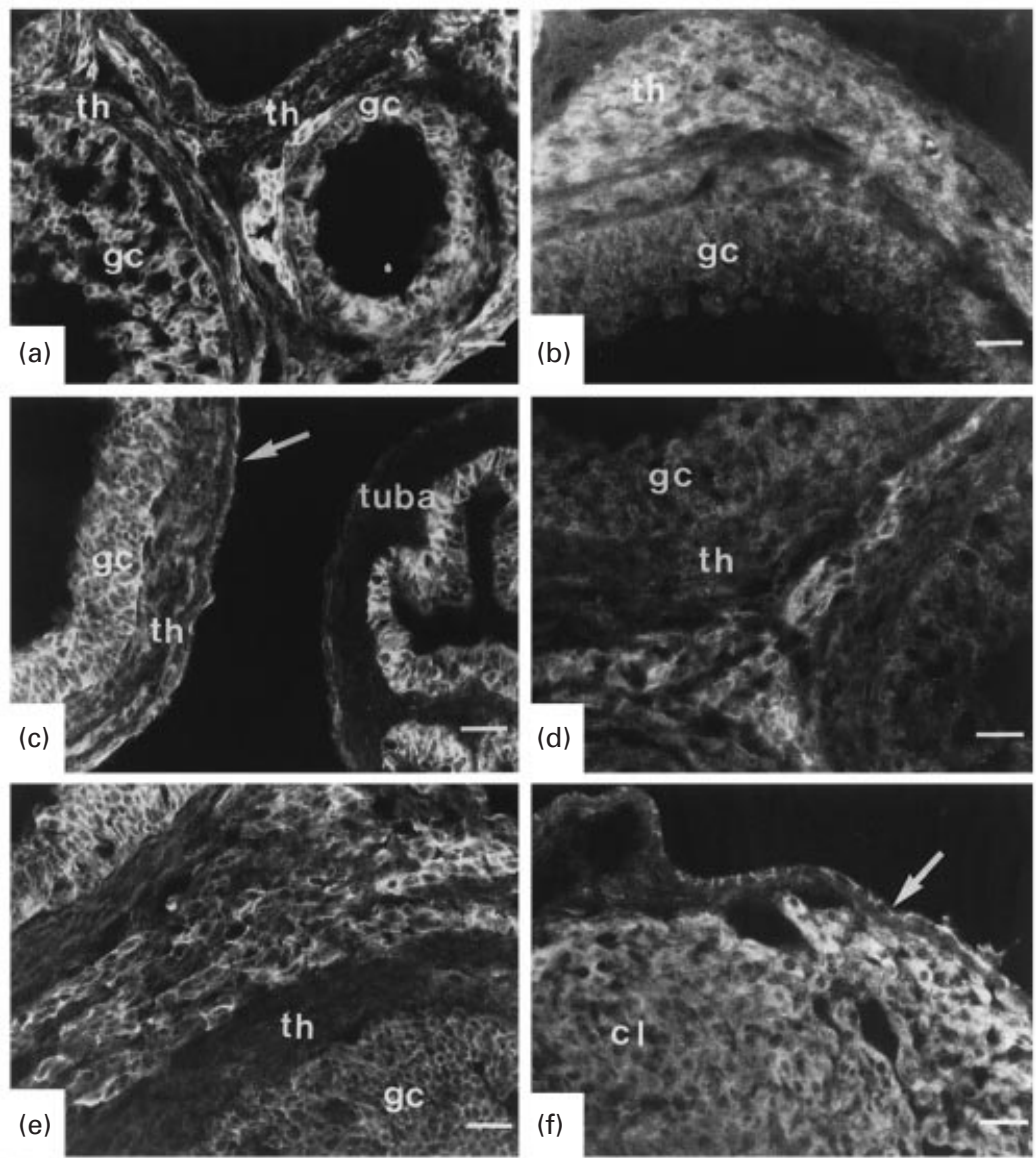

Fig. 7. Immunohistochemical localization of $\beta$-catenin during the follicular and luteal phase in rats. (a) Antral follicles of an immature ovary (day 25). (b) Preovulatory follicle (day 27). (c) Ovulatory follicle at $4 \mathrm{~h}$ after hCG (left) and the adjacent oviduct (right). (d) Ovulatory follicle at $8 \mathrm{~h}$ after hCG. (e) Ovulatory follicle at $12 \mathrm{~h}$ after hCG. (f) Corpus luteum of a cyclic ovary. Arrows show the surface epithelial cells. cl: corpus luteum; gc: granulosa cells; tuba: oviduct; th: theca cells. Scale bars represent $50 \mu \mathrm{m}$.

cells are of mesenchymal origin and therefore should not contain this cadherin. In the present study, both the immunohistochemistry and the immunoblotting demonstrated expression of E-cadherin in the theca and interstitial cells of the rat ovary. The presence of E-cadherin in nonepithelial cells has been demonstrated in other studies (Shimamura et al., 1992), indicating that the expression of this cadherin is not restricted to cells of epithelial origin.

Another observation that demonstrates species differences regarding the cellular localization of E-cadherin is expression in the surface epithelium of both the pig (Ryan et al., 1996) and the rat ovary (this study). These findings are in contrast to the human ovary; E-cadherin was not detectable in the epithelium covering the surface of menopausal and postmenopausal ovaries (Maines-Bandiera and Auersperg, 1997; Sundfeldt et al., 1997). Sundfeldt et al. (1997) reported the presence of E-cadherin in inclusion cysts and ovarian tumours of epithelial origin but not in a tumour derived from steroid-producing cells (thecoma). The role of Ecadherin in the surface epithelium of the pig and rat ovary is unclear, but in vitro studies using rat surface epithelial cells indicated that another member of the cadherin family, Ncadherin, could maintain cell viability and was involved in the control of calcium homeostasis (Gulati and Peluso, 1997). Moreover, $\mathrm{N}$-cadherin was also detected in granulosa cells in the rat ovary (Peluso et al., 1996) and in the intact mouse ovary (MacCalman et al., 1995). These findings are in agreement with earlier observations that $\mathrm{N}$-cadherin is largely detected extra-junctionally, whereas the expression of E-cadherin is mainly confined to adherens junctions (Geiger and Ayalon, 1992).

The physiological significance of the low expression of Ecadherin in granulosa cells of growing antral and preovulatory follicles in the present study is not clear. One possibility is that these cells enter a gonadotrophin-dependent proliferative phase (McNatty et al., 1983; Piontkewitz et al., 1997) when tight cell-cell adhesion with adherens junctions would interfere with proliferation. The observation of loosely attached granulosa cells in the ovulating follicle that are expelled together with the oocyte (Bjersing and Cajander, 1974) is also compatible with a reduced number or no adherens junctions in these cells. In contrast, the interstitial 


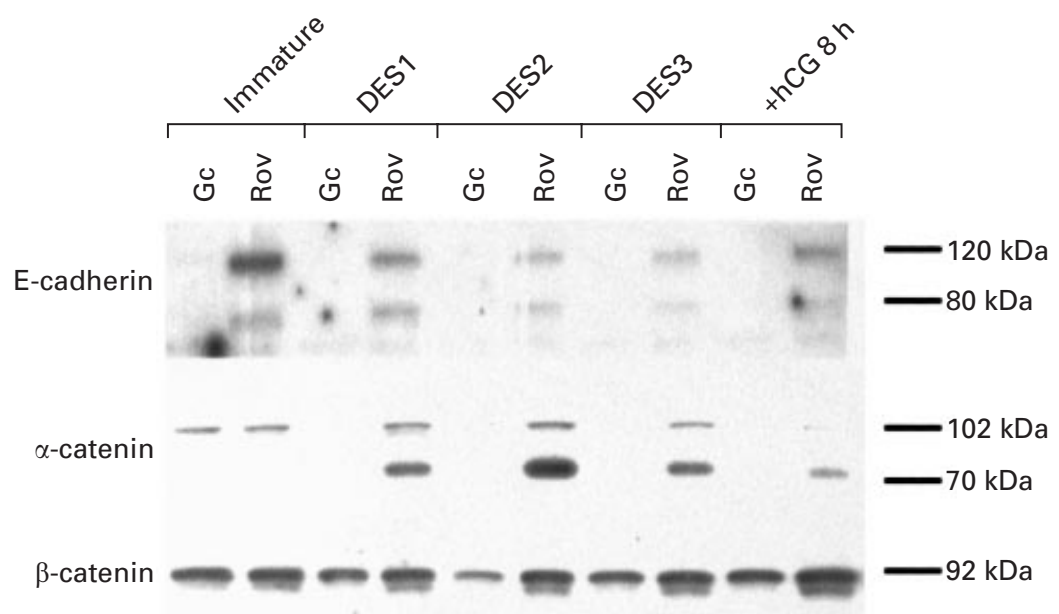

Fig. 8. Immunoblotting of E-cadherin and $\alpha$ - and $\beta$-catenin in immature rat ovaries and in rat ovaries after injection of diethylstilboestrol (DES) twice a day for 1, 2 or 3 days (DES1, DES2, DES3) and after hCG $(8 \mathrm{~h})$. The ovaries were separated into granulosa cells (Gc) and residual ovarian tissues (Rov).

and theca cells expressed high concentrations of E-cadherin in immature and preovulatory ovaries and also immediately after hCG $(4 \mathrm{~h})$. The mesenchymal-derived theca cells surround both the follicle and the outer layer of granulosa cells, providing structural integrity for the follicle. Other studies have implied that theca cells can regulate proliferation of granulosa cells by the production of different growth factors (Parrott et al., 1994). The expression of E-cadherin in theca cells, as described in the present study, may play a role in such theca cell-granulosa cell interactions. Enterocytes with a perturbed expression of E-cadherin had an increased proliferation rate (Hermiston and Gordon, 1995). Furthermore, expression of E-cadherin was also associated with a 'barrier function' in the intestinal epithelium (Hermiston and Gordon, 1995). It is possible that E-cadherin has a similar role in the theca and interstitial cells in which a 'barrier function' would limit the accessibility of the immune system to the follicular compartment during folliculogenesis. The influx of immune cells to the preovulatory follicle in response to the LH surge and the role of these cells in ovulation was described by Brännström et al. (1993). In the present study, immunoblotting and immunohistochemistry demonstrated a decrease in E-cadherin in theca and interstitial cells and residual ovarian tissues at $8 \mathrm{~h}$ and $12 \mathrm{~h}$ after hCG. This effect might be a facilitating factor for the extra-vasation of macrophages and neutrophils and the subsequent release of cytokines that promote the ovulation (Brännström et al., 1993) as well as for proliferation and migration of cells for luteal formation (Jablonka-Shariff et al., 1993).

Treatment with DES was not sufficient to obtain measurable amounts of E-cadherin in granulosa cells. In contrast, oestrogens resulted in a decrease in E-cadherins in the residual ovarian tissues. The stimulatory effect of oestrogen on cadherins in granulosa cells reported by Blaschuk and Farookhi (1989) and MacCalman et al. (1994a) was probably due to an effect on N-cadherin, since the antibody used (Blaschuk and Farookhi, 1989) recognizes most forms of cadherins. The presence of $\mathrm{N}$-cadherin in granulosa cells has been described in several studies (MacCalman et al., 1995; Peluso et al., 1996; Farookhi et al., 1997; Trolice et al., 1997). A transient increase in E-cadherin mRNA in the mouse ovary (MacCalman et al., 1994a) and uterus was described after oestradiol treatment (MacCalman et al., 1994b). However, Potter et al. (1996) reported that oestradiol resulted in the inactivation of E-cadherin in mouse uterine epithelial cells in vivo, including an increased proteolytic cleavage of the soluble $80 \mathrm{kDa}$ fragment. An increase in this fragment was not observed in theca cells or residual ovarian tissues after DES treatment in the present study. A stimulatory role for oestrogens in cell-cell interactions might therefore be restricted to the formation of gap junctions in granulosa cells (Merk et al., 1972).

The pattern of expression of $\alpha$-catenin was similar to that of E-cadherin and there were only minor changes in the content during the follicular and early luteal phases. However, both DES and gonadotrophins (hCG) resulted in a decrease in $\alpha$-catenin in granulosa cells. One difference between E-cadherin and $\alpha$-catenin was the localization of $\alpha$ catenin to the granulosa cells of immature and preovulatory follicles. The content of $\alpha$-catenin in granulosa cells was equivalent to the those found in both theca and interstitial cells at these two stages of follicular development. Rimm et al. (1995) demonstrated direct binding between $\alpha$-catenin and actin in vitro. Ben-Ze'ev and Amsterdam (1987) reported that $\mathrm{FSH}$ decreased cytoskeletal proteins like actin in granulosa cells in vitro. A decrease of $\alpha$-catenin was also observed in granulosa cells in response to gonadotrophins in vivo in the present study, indicating that modulation of cytoskeletal proteins and associated proteins, for example $\alpha$ catenin, is of importance for the differentiation of granulosa cells (Ben-Ze'ev and Amsterdam, 1987). The distribution of $\beta$-catenin was similar to that of $\alpha$-catenin, in all types of ovarian cell, including granulosa cells. A slight increase was detected in granulosa cells of preovulatory follicles compared with the immature ovary. However, no major effect of DES or gonadotrophins was noted. Regulation of 
catenins by pituitary hormones or steroids has not been reported, although retinoids were shown to stabilize $\beta$ catenin in breast cancer cells (Byers et al., 1996).

A pattern of expression of catenins distinct from that of Ecadherin, as observed in the granulosa cells in the present study, was also described during embryogenesis in mesodermal cells, and in the adult liver and heart of the mouse (Butz and Larue, 1995). In these tissues, the catenins were proposed to be associated with other cadherins, for example N-cadherin (Wheelock and Knudsen, 1991). Ncadherin is expressed in rat granulosa cells both in vivo (Farookhi et al., 1997) and in vitro (Peluso et al., 1996; Trolice et al., 1997). Trolice et al. (1997) suggested a function for Ncadherin in cell-cell adhesion to maintain steroid synthesis and to prevent apoptosis in vitro. The results of the present study showed that apoptotic granulosa cells do not express E-cadherin in vivo. Therefore, it is possible that expression of E-cadherin is important to maintain cell viability and thus to prevent apoptosis. Such functions might also explain the strong expression of E-cadherin in preantral follicles in the centre (medulla) of immature and preovulatory ovaries. The restricted and transient expression of E-cadherin in granulosa cells might be associated with the recruitment of follicles and thus play an 'anti-apoptotic' function to 'protect' the follicles for subsequent cycles. However, further in vitro experiments with transfected granulosa cells expressing Ecadherin and cultured without the hormonal support known to prevent apoptosis are required to evaluate this theory.

In conclusion, this study does not confirm the findings of other reports (Farookhi and Blaschuk, 1989; Ryan et al., 1996) in which the expression of E-cadherin was confined to the granulosa cells of antral and preovulatory follicles. In contrast, E-cadherin was mainly localized to theca, interstitial and surface epithelial cells; gonadotrophins and oestrogen (DES) had only a minor influence on expression. The pattern of expression of E-cadherin-catenin complexes involved in adherens junctions reflects the cell-cell adhesion between theca and interstitial cells, which is important in the maintenance of integrity in these ovarian compartments during folliculogenesis. Furthermore, the difference in cellular distribution between E-cadherin and catenins indicates additional functions of the catenins, for example involvement in cytoskeletal functions ( $\alpha$-catenin) and intracellular signalling pathways ( $\beta$-catenin).

This study was supported by the Swedish Medical Research Council (to L. Hedin: grant 10375, 12605), the Foundations of Hjalmar Svensson, Assar Gabrielsson, Axel and Margaret Ax:sonJohnson, Ollie and Elof Ericsson, the King Gustav V Jubilee Clinic Cancer Research Foundation, the Royal Academy of Arts and Sciences in Göteborg and the Göteborg Medical Society. A postdoctoral fellowship to Y. Piontkewitz was provided by the Wenner-Gren Foundation.

\section{References}

Amsterdam A, Plehn-Dujowich D and Suh BS (1992) Structure-function relationships during differentiation of normal and oncogene-transformed granulosa cells Biology of Reproduction 46 513-522

Behrens J, von Kries PJ, Kuhl M, Bruhn L, Wedlich D, Grosschedl R and
Birchmeier W (1996) Functional interaction of $\beta$-catenin with the transcription factor LEF-1 Nature 382 638-642

Ben-Ze'ev A and Amsterdam A (1987) In vitro regulation of granulosa cell differentiation Journal of Biological Chemistry $2625366-5376$

Billig H, Furuta I and Hsueh AJ (1993) Estrogens inhibit and androgens enhance ovarian granulosa cell apoptosis Endocrinology 133 2204-2212

Billig H, Furuta I and Hsueh AWJ (1994) Gonadotropin-releasing hormone directly induces apoptotic cell death in the rat ovary: biochemical and in situ detection of deoxyribonucleic acid fragmentation in granulosa cells Endocrinology 134 245-251

Bjersing L and Cajander S (1974) Ovulation and the mechanism of follicular rupture. I. Light microscopic changes in rabbit ovarian follicles prior to induced ovulation Cell and Tissue Research 149 287-300

Blaschuk OW and Farookhi R (1989) Estradiol stimulates cadherin expression in rat granulosa cells Developmental Biology 136 564-567

Brännström M, Mayrhofer G and Robertson SA (1993) Localisation of leukocyte subsets in the rat ovary during the periovulatory period Biology of Reproduction 48 277-286

Bronstein I, Voyta LC, Murphy OJ, Bresnick L and Kricka LJ (1992) Improved chemiluminescent western blotting procedure BioTechniques 12 748-753

Butz S and Larue L (1995) Expression of catenins during mouse embryonic development and in adult tissues Cell Adhesion and Communication 3 337-352

Byers S, Pishvaian M, Crockett C, Peer C, Tozeren A, Sporn M, Anzano M and Lechleider R (1996) Retinoids increase cell-cell adhesion strength, $\beta$ catenin protein stability, and localisation to the cell membrane in a breast cancer cell line: a role for serine kinase activity Endocrinology 137 3265-3273

Damsky CH, Richa J, Solter D, Knudsen K and Buck CA (1983) Identification and purification of a cell surface glycoprotein mediating intercellular adhesion in embryonic and adult tissue Cell 34 455-466

Farookhi R and Blaschuk OW (1989) E-cadherin may be involved in FSHstimulated responses in rat granulosa cells. In Growth Factors and the Ovary pp 257-265 Ed. AN Hirshfield. Plenum Press, New York

Farookhi R, Geng C-H, MacCalman CD and Blaschuk OW (1997) Hormonal regulation of $N$-cadherin mRNA levels in rat granulosa cells Annals of the New York Academy of Science 816 165-172

Geiger B and Ayalon O (1992) Cadherins Annual Review of Cell Biology 8 307-332

Gulati R and Peluso JJ (1997) Opposing action of hepatocyte growth factor and basic fibroblast growth factor on cell contact, intracellular free calcium levels, and rat ovarian surface epithelial cell viability Endocrinology 138 1847-1856

Gumbiner BM and McCrea PD (1993) Catenins as mediators of the cytoplasmic functions of cadherins Journal of Cell Science 17 155-158

Hermiston ML and Gordon JI (1995) In vivo analysis of cadherin function in the mouse intestinal epithelium: essential roles in adhesion, maintenance of differentiation, and regulation of programmed cell death Journal of Cell Biology 129 489-506

Jablonka-Shariff A, Grazul-Bilska AT, Redmer DA and Reynolds LP (1993) Growth and cellular proliferation on ovine corpora lutea throughout the estrous cycle Endocrinology 133 1871-1879

Khan-Dawood FS, Yang J and Dawood Y (1996a) Immunocytochemical localisation and expression of E-cadherin and $\beta$-catenin in the human corpus luteum Molecular Human Reproduction 2 753-757

Khan-Dawood FS, Yang J, Ozigi AA and Dawood Y (1996b) Immunocytochemical localisation and expression of E-cadherin, $\beta$-catenin, and plakoglobulin in the baboon (Papio anubis) corpus luteum Biology of Reproduction 55 246-253

Louvet JP, Harman SM and Ross GT (1975) Effects of human chorionic gonadotropin, interstitial cell stimulating hormone and human folliclestimulating hormone on ovarian weights in estrogen-primed hypophysectomized immature female rats Endocrinology 96 1179-1186

MacCalman CD, Farookhi R and Blaschuk OW (1994a) Estradiol regulates Ecadherin mRNA levels in the surface epithelium of the mouse ovary Clinical and Experimental Metastasis 12 276-282

MacCalman CD, Farookhi R and Blaschuk OW (1994b) Estradiol and progesterone regulate E-cadherin mRNA levels in the mouse uterus Endocrine Journal 2 1-6

MacCalman CD, Farookhi R and Blaschuk OW (1995) Estradiol regulates Ncadherin mRNA levels in the mouse ovary Developmental Genetics 16 20-24

McNatty KP, Hillier DG, van den Boogaard AM, Trimbos-Kemper TC, Reichert LE and van Hall EV (1983) Follicular development during the luteal phase of the human menstrual cycle Journal of Clinical Endocrinology and Metabolism 56 1022-1031

Maines-Bandiera SL and Auersperg N (1997) Increased E-cadherin 
expression in ovarian surface epithelium: an early step in metaplasia and dysplasia? International Journal of Gynecological Pathology 16 250-255

Merk FB, Botticelli CR and Albright JJ (1972) An intercellular response to oestrogen by granulosa cells in the rat ovary: an electron microscope study Endocrinology 90 992-1007

Molenaar M, van de Wetering M, Oosterwegel M, Peterson-Maduro J, Godsave S, Korinek V, Roose J, Destrée O and Clevers H (1996) XTct-3 transcritption factor mediates $\beta$-catenin-induced axis formation in Xenopus embryos Cell 86 391-399

Nordenström K and Hamberger L (1981) Influence of gonadotrophins on cAMP formation in theca cells isolated from pre-ovulatory rat follicles Acta Endocrinologica 96 534-540

Parrot JA, Vigne J-L, Chu BZ and Skinner MK (1994) Mesenchymal-epithelial interactions in the ovarian follicle involve keratinocyte and hepatocyte growth factor production by thecal cells and their action on granulosa cells Endocrinology 135 569-575

Peluso JJ, Pappalardo A and Trolice MP (1996) N-cadherin-mediated cell contact inhibits granulosa cell apoptosis in a progesterone-independent manner Endocrinology 137 1196-1203

Piontkewitz Y, Sundfeldt K and Hedin L (1997) The expression of c-myc during follicular growth and luteal formation in the rat ovary in vivo. Journal of Endocrinology 152 395-406

Potter SW, Gaza G and Morris JE (1996) Estradiol induces E-cadherin degradation in mouse uterine epithelium during the estrous cycle and early pregnancy Journal of Cell Physiology 169 1-14
Richards JS (1994) Hormonal control of gene expression in the ovary Endocrine Reviews 15 725-751

Rimm DL, Koslov ER, Kebriaei P, Cianci CD and Morrow JS (1995) $\alpha_{1}(E)-$ catenin is an actin-binding and -bundling protein mediating the attachment of F-actin to the membrane adhesion complex Proceedings National Academy of Sciences USA 92 8813-8817

Ryan PL, Valentine AF and Bagnell CA (1996) Expression of epithelial cadherin in the developing and adult pig ovary Biology of Reproduction 55 1091-1097

Shimamura K, Takahashi T and Takeichi M (1992) E-cadherin expression in a particular subset of sensory neurons Developmental Biology 152 242-254

Sundfeldt K, Piontkewitz Y, Ivarsson K, Nilsson O, Hellberg P, Brännström M, Janson PO, Enerbäck S and Hedin L (1997) E-cadherin expression in human epithelial ovarian cancer and normal ovary International Journal of Cancer 74 275-280

Takeichi M (1991) Cadherin cell adhesion receptors as morphogenetic regulator Science 251 1451-1455

Trolice MP, Pappalardo A and Peluso JJ (1997) Basic fibroblast growth factor and $\mathrm{N}$-cadherin maintain rat granulosa cell and ovarian surface epithelial cell viability by stimulating the tyrosine phosphorylation of the fibroblast growth factor receptors Endocrinology 138 107-113

Wheelock M and Knudsen KA (1991) N-cadherin-associated proteins in chicken muscle Differentiation 46 35-42 